\title{
Ethnic differences in 1-year follow-up effect of the Dutch Schoolgruiten Project - promoting fruit and vegetable consumption among primary-school children
}

\author{
Nannah I Tak*, Saskia J te Velde and Johannes Brug \\ EMGO Institute, VU University Medical Center, Van der Boerchorststraat 7, 1081 BT Amsterdam, \\ The Netherlands
}

Submitted 20 September 2006: Accepted 28 March 2007: First published online 5 July 2007

\begin{abstract}
Objective: To evaluate the effect of a primary school-based intervention providing free fruit and vegetables (F\&V), separately for children of Dutch and of nonWestern ethnicity.

Setting: Primary schools in two regions (west and east) in The Netherlands.

Design and methods: Participating schoolchildren and their parents completed questionnaires at baseline and 1 year later, including questions on usual F\&V intake, potential determinants and general demographics. Primary outcomes were the usual fruit intake and the usual vegetable intake as assessed by parentand child self-reported food frequency measures. Secondary outcome measures were child- or parent-reported taste preference, knowledge of daily recommendations, availability, and accessibility for fruit intake. Multilevel regression analyses were used to assess differences at follow-up adjusted for baseline values between the control and intervention group using both child and parent reports.

Subjects: Five hundred and sixty-five children of Dutch ethnicity and 388 children of non-Western ethnicity (mean age 9.9 years at baseline) and their parents.

Results: Children of non-Western ethnicity in the intervention group reported a significantly higher vegetable intake (difference $=20.7 \mathrm{~g} \mathrm{day}^{-1}$, 95\% confidence interval $(\mathrm{CI})=7.6-33.7)$. A significant positive intervention effect was also found for fruit intake for children of Dutch ethnicity (difference $=0.23$ pieces day ${ }^{-1}, 95 \%$ $\mathrm{CI}=0.07-0.39$ ). No significant effects in intake were observed based on parent reports. Significant positive intervention effects were also found for perceived accessibility among children of non-Western ethnicity, as well as for parentreported taste preference of their child among children of non-Western ethnicity and boys of Dutch ethnicity.

Conclusion: Providing children with free F\&V had some positive effects on childreported intakes and important correlates of intakes.
\end{abstract}

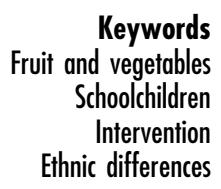

In many Western countries including The Netherlands, schoolchildren often do not comply with dietary recommendations. Notably, as shown in a recent European study, fruit and vegetable $(\mathrm{F} \& \mathrm{~V})$ intakes are lower than national guidelines ${ }^{1,2}$.

Epidemiological evidence for an association between eating enough $\mathrm{F} \& \mathrm{~V}$ and decreased risk for chronic metabolic diseases like obesity, hypertension and diabetes mellitus type 2 is convincing ${ }^{3,4}$. Therefore, various interventions have been developed aiming to increase F\&V intakes among children. Food habits acquired in childhood to a certain extent track into adolescence and adulthood ${ }^{5}$, arguing for the promotion of adequate $\mathrm{F} \& \mathrm{~V}$ consumption among schoolchildren ${ }^{6-8}$. Moreover, behavioural habits in children may not be as firmly rooted as in adults?.

The Dutch recommendations for F\&V intake for 10-12year-old children are two pieces of fruit (about 200-250 g) and $150-200 \mathrm{~g}$ of vegetables per day ${ }^{10}$. In The Netherlands, a number of interventions have been developed to promote compliance to these recommendations ${ }^{11}$. The largest-scale Dutch intervention is 'Schoolgruiten', which is a Dutch acronym for 'school fruits and vegetables'. The Schoolgruiten Project is meant to grow into a nationwide campaign for primary-school children, but started with a pilot phase in which the intervention was tested in a controlled design, to inform further improvement of the intervention or justify further implementation. 
In The Netherlands, especially in the major cities in the western part of the country, a growing minority, in some cities up to $50 \%$ of the children, has a non-Western background; at least one of their parents was born in a non-Western country, especially Morocco, Turkey, Surinam or the Netherlands Antilles. Evidence suggests that these children have different eating patterns, including different $F \& V$ intakes, than children of Dutch ethnicity $^{12-16}$. Furthermore, intervention studies hardly ever look at differential effects according to such factors as ethnicity, while it is important to explore such possible moderators to identify special interest groups. Since the Schoolgruiten Project was not specifically tailored to ethnic minority groups, and because some of these minority groups have higher mean intake levels, it might be expected that the intervention is less effective in these groups.

In summary, the aim of the present study was to evaluate the 1-year follow-up effect of the Schoolgruiten Project regarding F\&V consumption and important correlates $^{17}$ of F\&V consumption among European schoolchildren $^{18-21}$, i.e. knowledge of recommendations, taste preferences, availability and accessibility. This was done separately for children of Dutch and of non-Western ethnicity. Furthermore, interactions with gender and educational level of the parents were explored, and further stratification was carried out accordingly. We hypothesised that the intervention would have a significant effect on F\&V intakes and that the intervention would be less effective among the children of non-Western ethnicity compared with the ethnic Dutch children.

\section{Methods}

\section{The Schoolgruiten Project}

Since earlier studies and reviews indicate that taste preferences, availability and accessibility are important determinants of F\&V consumption among children ${ }^{19,21}$, and because intakes should be promoted through changes in such presumed mediators ${ }^{22}$, the main strategies within the Schoolgruiten Project targeted these factors. First, availability and accessibility of F\&V at school was improved through an F\&V scheme. The children in the intervention group received a piece of fruit or ready-toeat vegetables (cherry tomatoes, baby carrots) for free twice a week at the mid-morning break. The aim of the Schoolgruiten Project was that all children should eat the piece of fruit or vegetable together in their own classroom. Apart from increasing availability and accessibility, this F\&V scheme was also supposed to increase the children's exposure to F\&V. Repeated exposure is an important determinant of taste preferences ${ }^{23}$.

Additionally, a school curriculum, developed and carefully pre-tested by the Netherlands Nutrition Center Foundation that aimed to increase knowledge and skills related to $\mathrm{F} \& \mathrm{~V}$ consumption, was offered to the intervention schools. The intervention schools were not obliged to use this curriculum, but they were encouraged to do so.

\section{Recruitment of schools and study sample}

The Schoolgruiten Project was implemented in seven cities of The Netherlands. These seven cities were indicated by the Dutch Ministry of Public Health, Welfare and Sport. Because of time and financial constraints, only two of these cities were included in the evaluation study. These were The Hague, a major city in the west of The Netherlands, and Almelo, a medium-sized city in the east.

The design of the evaluation study was quasi experimental, with a pre- and post-test, and an intervention and a control group. Since the intervention cities were decided upon by the authorities, no randomisation was possible. The Schoolgruiten research group selected three control cities: Zoetermeer and Leidschendam close to The Hague, and Hengelo, which is close to Almelo.

Participating children were from the 4 th grade (age 9-10 years) ${ }^{24}$. All 4 th grades from primary schools in the cities were eligible for participation, and schools were randomly approached by telephone and invited to participate in this survey. Recruitment ended when 50 schools had agreed to participate, ensuring a sample of at least 600 children of the 4th grade in the intervention as well as in the control group.

For one city (Hengelo) records were kept to assess school willingness to participate. Sixteen schools were invited to participate in that city of which half agreed immediately, four refused and another four schools had to consult their external school board before confirming participation. Only the eight schools that agreed immediately were included in the study. Similar procedures and rates of agreement were found in the other cities.

The baseline measurement was conducted before the intervention started and the follow-up measurement was conducted exactly one year later. The baseline survey was conducted in The Hague, Zoetermeer and Leidschendam in the spring of 2003 and in Almelo and Hengelo in the autumn of 2003.

For the evaluation study both the children and their parents completed questionnaires about the child's intake and potential determinants, allowing evaluation based on child as well as parent reports.

\section{Procedure}

Children completed the questionnaire within one school hour guided by their own teacher in their classroom, based on a written administration protocol provided by the research staff.

At baseline and follow-up the children brought home a parent questionnaire to be completed preferably by the 
parent who usually took care of the child's meals. The children received a small present when they returned the completed parent questionnaire.

All children of the 4th grade who were present on the day and hour of administration completed the questionnaires - 1328 children (100\%) and 1070 parents at baseline (response of $81 \%$ ). Five schools were no longer willing to participate at follow-up, resulting in fewer children at follow up - 1140 children (86\%) and 931 parents (response of $70 \%$ ). Since the study purpose was to evaluate the 1-year follow-up effects of this intervention, only the children who completed the questionnaire at baseline and follow-up were included for analyses. Furthermore, only children who completed all questions on fruit intake or all questions on vegetable intake were included in analyses for fruit or vegetables. The same applied for the parental reports of the child's F\&V intake.

A total of 565 (232 intervention and 333 control) children of Dutch ethnicity and a total of 388 (268 intervention and 120 control) children of non-Western ethnicity were included for analyses. Children with valid selfreported data on fruit and/or vegetable intake at baseline but not at follow-up were considered as dropouts. Dropout was due to the loss of five schools $(n=112)$, and because children moved to other places or schools, did not graduate to the next grade, were sick on the day of administration at follow-up $(n=194)$ or had missing F\&V reports at follow-up $(n=23)$. Children of Western ethnicity $(n=46)$ were not taken into account in all analyses.

Regarding parents, data were available for 458 (195 intervention and 263 control) parents of children of Dutch ethnicity and 247 (160 intervention and 87 control) parents of children of non-Western ethnicity. Parent data of children of Western ethnicity $(n=37)$ were excluded for this study. Dropout was due to the loss of five schools $(n=86)$, parents who moved, parents who had a child who did not graduate to the next grade or who were sick on the day of administration, parents who refused to complete the questionnaire at follow-up $(n=240)$ and missing F\&V intake reports $(n=2)$.

\section{Questionnaires}

Separate questionnaires for children and parents were developed, both based on the validated Pro Children questionnaires $^{25,26}$. By parallel questions in the two questionnaires, the usual intake of F\&V among the children was assessed with the Pro Children food frequency questions ${ }^{25,26}$. Taste preference, knowledge of recommendations, accessibility and availability of fruit were assessed with questions similar to those used in the Pro Children Study ${ }^{25,26}$. The parent questionnaire also included questions on the parent's country of birth, level of education, age, child's age and number of siblings. Information on the country of birth of parents was used to make distinctions between children of Dutch, non-Western and non-Dutch Western ethnicity (Europe (excluding Turkey), North America, Oceania, Indonesia or Japan), according to the definition of the Dutch Institute of Statistics ${ }^{27}$. When at least one of the parents was born in a non-Western country the child was considered as of nonWestern ethnicity. Based on the highest educational level of one of the parents, a division into three groups (low, primary school or pre-vocational training; medium, high school or medium-level vocational training; high, highlevel vocational training, college or university training) was performed.

A more detailed description of the questions and answer alternatives of the questionnaire has been published previously ${ }^{28}$.

\section{Statistical analyses}

Since in the present project both child- and parent-report data were available, and it is not clear which data are most valid and sensitive for evaluation of school-based interventions $^{28}$, all analyses were performed on both datasets.

Selective dropout and selective parent participation were assessed by logistic regression analyses with gender, parent educational level, region of residence of the children (categorical variables) and consumption of fruit or vegetables at baseline (continuous variables) as independent variables. Means, standard deviations (SDs) and percentages were calculated to describe the key variables.

To describe unadjusted outcomes, paired samples $t$-tests, $t$-tests for independent samples, paired Wilcoxon tests and $\chi^{2}$ tests were used. To assess the adjusted effect of the intervention regarding the primary outcomes, multilevel regression analyses were performed to compare fruit or vegetable intakes at follow-up (dependent variable) between the intervention (1) and the control group (0) (dichotomous independent variable). A multilevel analysis takes into account that effects may cluster within schools/classes. Analyses were further adjusted for children's age, gender, parental education level, region of residence, and baseline intake levels. The estimated regression coefficient reflects the adjusted difference in fruit/vegetable consumption between the intervention and control group. The residuals of the regression analyses were checked for normality and were considered acceptable.

Effect modification by gender and educational level was assessed by including gender $\times$ group or educational level $\times$ group interaction terms in the model. When these terms approached significance $(P<0.10)$, analyses were stratified.

As suggested by Twisk and Proper ${ }^{29}$, the change between baseline and follow-up in the categorical variables was assessed by means of multilevel multinomial logistic regression analyses. For these analyses the 
dependent variables were newly constructed categorical variables, with three categories, which were defined by their scores on baseline and follow-up. The categories were: 'stable high/increased' (reference group, 0), 'stable low' (1) and 'decreased' (2). Again, group (intervention $=1$, control $=0$ ) was the independent variable and the analyses were adjusted for children's age, gender, education level of the parents and region of residence. The significance level was set at $P<0.05$. The estimated odds ratios (ORs) reflect the odds of being in the specific category for the intervention group compared with being in the reference category (='stable high/increased'). The explorative data analyses were done using SPSS 11.0 (SPSS Inc., 1999). The multilevel analyses were conducted

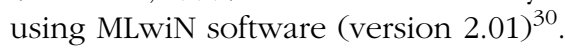

\section{Results}

\section{Dropout and non-participating parents}

Children of Dutch ethnicity

Due to the loss of five schools (three control schools and two intervention schools), selective dropout was found for parents in the control group (OR $=1.69$, 95\% confidence interval $(\mathrm{CI})=1.14-2.51)$, for those residing in the eastern region (child data: $\mathrm{OR}=2.54,95 \% \mathrm{CI}=1.45-4.43$; parent data: $\mathrm{OR}=2.48,95 \% \mathrm{CI}=1.58-3.87$ ) and for children who reported lower fruit intake at baseline (OR $=0.79$, 95\% CI $=0.62-0.99)$.

At baseline, children of Dutch ethnicity of non-participating parents were more likely to live in the western region $(\mathrm{OR}=2.86,95 \% \mathrm{CI}=1.17-6.94)$ and to be a boy $(\mathrm{OR}=2.79,95 \% \mathrm{CI}=1.23-6.30)$. At follow-up the gender difference disappeared, while the difference regarding region of residence remained ( $\mathrm{OR}=2.91$, 95\%
$\mathrm{CI}=1.83-4.62)$. At follow-up, the children from nonparticipating parents were more likely to be in the control group $(\mathrm{OR}=1.70,95 \% \mathrm{CI}=1.14-2.55)$.

\section{Children of non-Western ethnicity}

Again, due to the loss of five schools, selective dropout was found in the control group (child data: $\mathrm{OR}=2.65$, 95\% CI $=1.44-4.85$; parent data: $\mathrm{OR}=1.92,95 \% \mathrm{CI}=$ 1.15-3.21), children who reported higher fruit intake at baseline $(\mathrm{OR}=1.33,95 \% \mathrm{CI}=1.04-1.71)$ and boys (OR $=1.64,95 \% \mathrm{CI}=1.01-2.65)$.

At baseline, non-participating parents were more likely to be in the control group $(\mathrm{OR}=2.75,95 \% \mathrm{CI}=$ 1.39-5.45), while at follow-up these parents were more likely to be in the intervention group (OR $=2.75$, 95\% $\mathrm{CI}=1.61-4.67)$.

\section{Characteristics}

Slightly more girls than boys participated (Table 1). The majority of the children were of Dutch ethnicity. At baseline, the age of all children ranged between 8.3 and 12.5 years; for parents this was 25.2-61.0 years.

\section{FEV intake (primary outcomes)}

\section{Children of Dutch ethnicity}

At baseline, the total sample of children of Dutch ethnicity (intervention and control children together) reported a mean daily fruit intake of $1.58(\mathrm{SD}=1.06)$ pieces and a mean daily vegetable intake of $97.9(\mathrm{SD}=44.3) \mathrm{g}$.

At follow-up the unadjusted analyses showed higher $\mathrm{F} \& \mathrm{~V}$ intake in the intervention than in the control group, except for the parent-reported fruit intake (Table 2). After adjustments, it appeared that the intervention group had significantly higher fruit intake than the control group

Table 1 Characteristics of the study population at baseline (child data)

\begin{tabular}{|c|c|c|c|c|c|c|c|c|c|c|}
\hline \multirow[b]{3}{*}{ Characteristic } & \multicolumn{5}{|c|}{ Children of Dutch ethnicity } & \multicolumn{5}{|c|}{ Children of non-Western ethnicity } \\
\hline & \multicolumn{2}{|c|}{ Intervention } & \multicolumn{2}{|r|}{ Control } & \multirow[b]{2}{*}{$P$-value* } & \multicolumn{2}{|c|}{ Intervention } & \multicolumn{2}{|r|}{ Control } & \multirow[b]{2}{*}{$P$-value } \\
\hline & $n$ & $\begin{array}{c}\text { Mean (SD) } \\
\text { or } \%\end{array}$ & $n$ & $\begin{array}{c}\text { Mean (SD) } \\
\text { or } \%\end{array}$ & & $n$ & $\begin{array}{c}\text { Mean }(S D) \\
\text { or } \%\end{array}$ & $n$ & $\begin{array}{c}\text { Mean (SD) } \\
\text { or } \%\end{array}$ & \\
\hline Age of the children (years) & 232 & $9.7(0.5)$ & 333 & $9.8(0.5)$ & 0.339 & 268 & $10.2(0.7)$ & 120 & $10.1(0.6)$ & 0.347 \\
\hline Age of the parents (years) & 208 & $39.1(4.1)$ & 294 & $40.3(4.4)$ & 0.401 & 158 & $37.0(5.9)$ & 87 & $39.0(6.5)$ & 0.452 \\
\hline \multicolumn{11}{|l|}{ Gender } \\
\hline $\begin{array}{l}\text { Boys } \\
\text { Educational level of the par }\end{array}$ & 118 & 50.9 & 158 & 47.4 & 0.424 & 123 & 45.9 & 60 & 50.0 & 0.454 \\
\hline Low & 39 & 18.0 & 51 & 16.0 & 0.080 & 107 & 50.0 & 28 & 25.9 & $<0.001$ \\
\hline Moderate & 95 & 43.8 & 115 & 36.0 & & 66 & 30.8 & 43 & 39.8 & \\
\hline High & 83 & 38.2 & 153 & 48.0 & & 41 & 19.2 & 37 & 34.3 & \\
\hline \multicolumn{11}{|l|}{ Number of siblings } \\
\hline 0 & 23 & 10.5 & 18 & 5.6 & 0.108 & 20 & 9.0 & 14 & 12.4 & 0.469 \\
\hline 1 & 112 & 51.1 & 183 & 56.4 & & 75 & 33.6 & 42 & 37.2 & \\
\hline 2 & 58 & 26.5 & 76 & 23.5 & & 56 & 25.1 & 21 & 18.5 & \\
\hline$\geq 3$ & 26 & 11.9 & 47 & 14.5 & & 72 & 32.3 & 36 & 31.9 & \\
\hline
\end{tabular}

SD - standard deviation.

*Estimated by $\chi^{2}$ test (independent categorical data). 
according to the child reports (difference $=0.23$ pieces day $^{-1}, 95 \%$ CI $=0.07-0.39$ ) (Table 3). No other significant differences were observed.

\section{Children of non-Western ethnicity}

At baseline, the total sample of children of non-Western ethnicity (intervention and control children together) reported a mean daily fruit intake of $2.02(\mathrm{SD}=1.17)$ pieces and a mean daily vegetable intake of 120.6 $(\mathrm{SD}=66.3) \mathrm{g}$.

A significant interaction $(P=0.084)$ with parental educational level was found for child-reported fruit intake, but after stratification no significant effect sizes were found in either group (data not shown).

At follow-up the children in the intervention group reported a significantly higher unadjusted vegetable intake than the children in the control group $(P=0.013)$ (Table 2), also after adjustment for the potential confounders $\quad$ (difference $=20.7 \mathrm{~g} \mathrm{day}^{-1}, 95 \% \mathrm{CI}=7.6-33.7$ ) (Table 3). No interactions or other significant differences were found for this subgroup.

\section{Determinants of fruit intake (secondary outcomes)}

\section{Children of Dutch ethnicity}

At baseline, $79 \%$ of the parents of children of Dutch ethnicity reported that their child liked fruit or liked fruit very much. This proportion did not differ between the intervention and control groups at baseline or follow-up (Table 4). However, when taking potential confounders into account, a significant intervention effect was observed. According to the parent data (but not the child data), boys in the intervention group were less likely to have decreased their liking of fruit between baseline and follow-up (Table 5).

The unadjusted analyses showed an increase in knowledge of the recommendations for fruit intake in the intervention group (Table 4), but no effect on knowledge of recommended intake levels was observed in the adjusted analyses (Table 5). No other effects on the determinants were observed (Table 5).

\section{Children of non-Western ethnicity}

At baseline, $75 \%$ of the parents in this subgroup reported that their child liked fruit or liked fruit very much. According to the parent data no significant differences for the determinants of fruit intake were observed between intervention and control groups (Table 4). We only observed an increased accessibility of fruit in the control group at follow-up.

According the child data, the unadjusted results indicated that the intervention group significantly increased their knowledge of recommendations for fruit intake, were more often allowed to take fruit without asking and 
Table 3 Indicators of effects of the intervention regarding fruit and vegetable intake from multilevel regression analyses conducted on child reports as well as parent reports, separately for children of Dutch and of non-Western ethnicity

\begin{tabular}{|c|c|c|c|}
\hline Primary outcome* & $n$ & $\beta$ & $95 \% \mathrm{Cl}$ \\
\hline \multicolumn{4}{|l|}{ Children of Dutch ethnicity } \\
\hline Parent report of fruit intake (pieces day ${ }^{-1}$ ) & 455 & 0.12 & $-0.01,0.24$ \\
\hline Child report of fruit intake (pieces day ${ }^{-1}$ ) & 519 & 0.23 & $0.07,0.39$ \\
\hline \multicolumn{4}{|l|}{ Parent report of vegetable intake $\left(\mathrm{g} \mathrm{day}^{-1}\right)$} \\
\hline Girlst & 238 & 8.03 & $-1.50,17.55$ \\
\hline Boys & 211 & 1.23 & $-6.70,9.16$ \\
\hline Child report of vegetable intake $\left(\mathrm{g} \mathrm{day}^{-1}\right)$ & 504 & 5.06 & $-2.29,12.41$ \\
\hline \multicolumn{4}{|l|}{ Children of non-Western ethnicity } \\
\hline Parent report of fruit intake (pieces day ${ }^{-1}$ ) & 234 & 0.09 & $-0.16,0.35$ \\
\hline Child report of fruit intake (pieces day ${ }^{-1}$ ) & 301 & 0.14 & $-0.11,0.39$ \\
\hline Parent report of vegetable intake $\left(\mathrm{g} \mathrm{day}^{-1}\right)$ & 226 & 2.78 & $-10.03,15.59$ \\
\hline Child report of vegetable intake $\left(\mathrm{g}\right.$ day $\left.^{-1}\right)$ & 287 & 20.68 & $7.63,33.72$ \\
\hline
\end{tabular}

$\beta$ - difference in primary outcome in the intervention group compared with the control group; $\mathrm{Cl}$ - confidence interval.

${ }^{\star}$ Analyses are adjusted for children's age, (gender), education level of the parents, region of residence of the children, and baseline levels of fruit or vegetable consumption.

+ A significant interaction for gender between the children of Dutch ethnicity $(P=0.078)$.

also perceived higher fruit availability at home at followup (Table 4).

Adjusted analyses on the parent data showed a significant effect for taste preference only. Children in the intervention group were less likely to have decreased their preferences for fruit between baseline and followup. In the adjusted child data significant effects were found for perceived accessibility (Table 5).

\section{Discussion}

The present study indicates that the Schoolgruiten Project had a significant effect on the fruit intake of children of Dutch ethnicity and on the vegetable intake of children of non-Western ethnicity, but these effects were found only in analyses based on the child-reported data.

A Danish study ${ }^{31}$ with a follow-up period of 5 weeks also showed positive effects for fruit intake. However, in the Danish study parents had to pay for the daily school F\&V. Positive effects of free school F\&V delivery were reported by Bere et $a l^{32}$ based on a study conducted in Norway; the intervention group reported an increase of approximately 0.9 portions of F\&V at 10 months' follow-up.

The effects of the Schoolgruiten Project fall within that same range. The Schoolgruiten Project was initiated outside an academic centre; it was planned, developed and implemented by a public-private partnership of the Netherlands Nutrition Center Foundation with the promotion office of Dutch F\&V producers. This partnership did try to combine intervention strategies that were tailored to important mediators of F\&V intake in primaryschool children, but because of time constraints was not able to work carefully according to established planning models, as was done, for example, in the similar Pro Children intervention ${ }^{33}$.
A disadvantage of the research design applied in the present study is that randomisation was not possible, since the Dutch government had indicated the intervention cities. Although our analyses indicated very few baseline differences between the intervention and control groups, the fact that schools were not randomly allocated may have introduced bias. Another bias may have occurred due to some selective dropout. However loss to follow-up was not a consequence of an autonomous decision of the child, but was primarily caused by dropout of five schools, and in some cases based on parental decisions.

Evaluation of school-based healthful nutrition promotion interventions should be based on accurate and valid assessments of intake levels and mediators of intakes ${ }^{8}$. Collecting accurate intake data based on observations or biomarkers is often possible in smaller-scale, carefully controlled efficacy studies, but not in larger-scale studies in real-life settings. Collecting blood samples in children introduces bias because of low participation rates $^{34,35}$. Food-frequency questionnaires are therefore generally used. Although these questionnaires rely on participants' memory and cognition, which may influence the accuracy of the reported intake, this bias is believed to be the same in the control as in the intervention group.

The Schoolgruiten intervention aimed at increasing availability and accessibility of F\&V and we indeed found that perceived accessibility was improved in the intervention group at follow-up, according to the data of the children of non-Western ethnicity. We also observed some favourable positive changes in the intervention group for taste preference. Unfortunately, we found no effects on knowledge of recommended intake levels, although the school curriculum did address these recommendations. This may be due to the fact that the curriculum was not adopted and implemented by all intervention schools. The curriculum materials were used at least once by only about $40 \%$ of the intervention schools. 
Table 4 Determinants of fruit intake at baseline and at follow-up in the intervention and the control group conducted on parent- and child-reported data, separately for children of Dutch and of non-Western ethnicity

\begin{tabular}{|c|c|c|c|c|c|c|c|c|c|c|c|c|}
\hline \multirow[b]{3}{*}{ Secondary outcome - FRUIT } & \multicolumn{5}{|c|}{ Intervention group } & \multicolumn{5}{|c|}{ Control group } & & \\
\hline & \multicolumn{2}{|c|}{ Baseline } & \multicolumn{2}{|c|}{ Follow-up } & \multirow[b]{2}{*}{$P$-value* } & \multicolumn{2}{|c|}{ Baseline } & \multicolumn{2}{|c|}{ Follow-up } & \multirow[b]{2}{*}{$P$-value* } & \multicolumn{2}{|c|}{ Comparison between groups $t$} \\
\hline & $n$ & $\%$ & $n$ & $\%$ & & $n$ & $\%$ & $n$ & $\%$ & & Baseline & Follow-up \\
\hline \multicolumn{13}{|l|}{ Children of Dutch ethnicity } \\
\hline \multirow{2}{*}{\multicolumn{13}{|c|}{$\begin{array}{l}\text { Parent data } \\
\text { Taste of the child }\end{array}$}} \\
\hline & & \multicolumn{11}{|c|}{ Taste of the child } \\
\hline Don't/like a few & 44 & 22.7 & 36 & 18.6 & 0.006 & 51 & 19.4 & 57 & 21.7 & 0.073 & 0.547 & 0.018 \\
\hline Like fruit & 88 & 45.3 & 83 & 42.7 & & 132 & 50.2 & 137 & 52.1 & & & \\
\hline Enjoy fruit very much & 62 & 32.0 & 75 & 38.7 & & 80 & 30.4 & 69 & 26.2 & & & \\
\hline \multicolumn{13}{|c|}{ Knowledge of parent about recommendations for fruit } \\
\hline Too little & 18 & 9.3 & 23 & 11.9 & 0.831 & 29 & 11.2 & 22 & 8.5 & 0.254 & 0.648 & 0.487 \\
\hline Satisfactory & 55 & 28.4 & 48 & 24.7 & & 65 & 25.1 & 66 & 25.4 & & & \\
\hline Good & 121 & 62.3 & 123 & 63.4 & & 165 & 63.7 & 172 & 66.1 & & & \\
\hline \multicolumn{13}{|c|}{ Is the child allowed to take fruit without asking? } \\
\hline No & 19 & 9.8 & 23 & 11.9 & 0.655 & 28 & 10.8 & 14 & 5.3 & 0.001 & 0.664 & 0.041 \\
\hline Sometimes & 29 & 14.9 & 25 & 12.9 & & 46 & 17.7 & 38 & 14.5 & & & \\
\hline Yes & 146 & 75.3 & 146 & 75.2 & & 186 & 71.5 & 210 & 80.2 & & & \\
\hline \multicolumn{13}{|l|}{ Fruit available at home } \\
\hline Never/sometimes & 10 & 5.2 & 5 & 2.6 & 0.059 & 6 & 2.3 & 9 & 3.4 & 0.317 & 0.107 & 0.595 \\
\hline Usually & 183 & 94.8 & 189 & 97.4 & & 251 & 97.7 & 252 & 96.6 & & & \\
\hline \multicolumn{13}{|l|}{ Child data } \\
\hline \multicolumn{13}{|l|}{ Taste of the child } \\
\hline Don't/like a few & 2 & 0.9 & 2 & 0.9 & 0.701 & 2 & 0.6 & 2 & 0.6 & 0.232 & 0.478 & 0.218 \\
\hline Like fruit & 60 & 26.4 & 57 & 25.1 & & 71 & 22.2 & 61 & 19.1 & & & \\
\hline Enjoy fruit very much & 165 & 72.7 & 168 & 74.0 & & 247 & 77.2 & 257 & 80.3 & & & \\
\hline \multicolumn{13}{|c|}{ Knowledge of child about recommendations for fruit } \\
\hline Too little & 68 & 31.6 & 52 & 23.0 & 0.004 & 78 & 24.7 & 84 & 26.5 & 0.602 & 0.171 & 0.625 \\
\hline Satisfactory & 65 & 30.2 & 67 & 29.6 & & 97 & 30.7 & 93 & 29.3 & & & \\
\hline Good & 82 & 38.2 & 107 & 47.4 & & 141 & 44.6 & 140 & 44.2 & & & \\
\hline \multicolumn{13}{|c|}{ Is the child allowed to take fruit without asking? } \\
\hline No & 29 & 12.8 & 20 & 8.8 & 0.007 & 50 & 15.9 & 24 & 7.5 & $<0.001$ & 0.018 & 0.025 \\
\hline Sometimes & 61 & 27.0 & 48 & 21.1 & & 114 & 36.2 & 101 & 31.7 & & & \\
\hline Yes & 136 & 60.2 & 159 & 70.1 & & 151 & 47.9 & 194 & 60.8 & & & \\
\hline \multicolumn{13}{|l|}{ Fruit available at home } \\
\hline Never/sometimes & 72 & 31.7 & 42 & 18.5 & $<0.001$ & 67 & 21.1 & 45 & 14.1 & 0.004 & 0.005 & 0.162 \\
\hline Usually & 155 & 68.3 & 185 & 81.5 & & 250 & 78.9 & 275 & 85.9 & & & \\
\hline \multicolumn{13}{|c|}{ Children of non-Western ethnicity } \\
\hline Parent data & & & & & & & & & & & & \\
\hline Taste of the child & & & & & & & & & & & & \\
\hline Don’t/like a few & 38 & 24.1 & 33 & 21.3 & 0.475 & 24 & 28.2 & 25 & 28.7 & 0.643 & 0.775 & 0.254 \\
\hline Like fruit & 61 & 38.6 & 59 & 38.1 & & 31 & 36.5 & 35 & 40.3 & & & \\
\hline Enjoy fruit very much & 59 & 37.3 & 63 & 40.6 & & 30 & 35.3 & 27 & 31.0 & & & \\
\hline
\end{tabular}


Table 4 Continued

\begin{tabular}{|c|c|c|c|c|c|c|c|c|c|c|c|c|}
\hline \multirow[b]{3}{*}{ Secondary outcome - FRUIT } & \multicolumn{5}{|c|}{ Intervention group } & \multicolumn{5}{|c|}{ Control group } & & \\
\hline & \multicolumn{2}{|c|}{ Baseline } & \multicolumn{2}{|c|}{ Follow-up } & \multirow[b]{2}{*}{$P$-value* } & \multicolumn{2}{|c|}{ Baseline } & \multicolumn{2}{|c|}{ Follow-up } & \multirow[b]{2}{*}{$P$-value* } & \multicolumn{2}{|c|}{ Comparison between groups $t$} \\
\hline & $n$ & $\%$ & $n$ & $\%$ & & $n$ & $\%$ & $n$ & $\%$ & & Baseline & Follow-up \\
\hline \multicolumn{13}{|c|}{ Knowledge of parent about recommendations for fruit } \\
\hline Too little & 19 & 12.3 & 18 & 11.5 & \multirow[t]{4}{*}{0.267} & 8 & 9.3 & 8 & 9.2 & \multirow[t]{3}{*}{0.696} & \multirow[t]{4}{*}{0.747} & \multirow[t]{3}{*}{0.448} \\
\hline Satisfactory & 57 & 36.8 & 49 & 31.2 & & 31 & 36.0 & 34 & 39.1 & & & \\
\hline Good & 79 & 50.9 & 90 & 57.3 & & 47 & 54.7 & 45 & 51.7 & & & \\
\hline \multicolumn{11}{|c|}{ Is the child allowed to take fruit without asking? } & & \\
\hline No & 3 & 1.9 & 4 & 2.5 & \multirow[t]{3}{*}{0.137} & 3 & 3.5 & 4 & 4.7 & \multirow[t]{3}{*}{0.041} & \multirow[t]{3}{*}{0.480} & \multirow[t]{3}{*}{0.526} \\
\hline Sometimes & 33 & 21.0 & 22 & 13.9 & & 22 & 25.9 & 9 & 10.6 & & & \\
\hline Yes & 121 & 77.1 & 132 & 83.6 & & 60 & 70.6 & 72 & 84.7 & & & \\
\hline \multicolumn{13}{|l|}{ Fruit available at home } \\
\hline Never/sometimes & 14 & 8.9 & 9 & 5.8 & \multirow[t]{2}{*}{0.439} & 7 & 8.0 & 6 & 7.0 & \multirow[t]{2}{*}{0.655} & \multirow[t]{2}{*}{0.816} & \multirow[t]{2}{*}{0.728} \\
\hline Usually & 143 & 91.1 & 145 & 94.2 & & 80 & 92.0 & 80 & 93.0 & & & \\
\hline \multicolumn{13}{|l|}{ Child data } \\
\hline \multicolumn{13}{|l|}{ Taste of the child } \\
\hline Don't/like a few & 1 & 0.4 & 1 & 0.4 & \multirow[t]{3}{*}{0.793} & 0 & 0 & 0 & 0 & 0.808 & 0.474 & 0.458 \\
\hline Like fruit & 56 & 22.3 & 54 & 21.5 & & 20 & 17.7 & 19 & 16.8 & & & \\
\hline Enjoy fruit very much & 194 & 77.3 & 196 & 78.1 & & 93 & 82.3 & 94 & 83.2 & & & \\
\hline Knowledge of child about re & & & & & & & & & & & & \\
\hline Too little & 75 & 31.8 & 54 & 22.0 & 0.017 & 32 & 29.6 & 33 & 29.7 & 0.556 & 0.205 & 0.184 \\
\hline Satisfactory & 85 & 36.0 & 91 & 37.0 & & 31 & 28.7 & 32 & 28.8 & & & \\
\hline Good & 76 & 32.2 & 101 & 41.0 & & 45 & 41.7 & 46 & 41.5 & & & \\
\hline Is the child allowed to take $f$ & & & & & & & & & & & & \\
\hline No & 9 & 3.6 & 3 & 1.2 & 0.010 & 6 & 5.4 & 5 & 4.4 & 0.695 & 0.022 & $<0.001$ \\
\hline Sometimes & 40 & 16.1 & 31 & 12.4 & & 31 & 27.7 & 31 & 27.4 & & & \\
\hline Yes & 200 & 80.3 & 215 & 86.4 & & 75 & 66.9 & 77 & 68.2 & & & \\
\hline Fruit available at home & & & & & & & & & & & & \\
\hline Never/sometimes & 68 & 27.3 & 49 & 19.6 & 0.009 & 26 & 23.2 & 25 & 22.1 & 0.827 & 0.412 & 0.580 \\
\hline Usually & 181 & 72.7 & 201 & 80.4 & & 86 & 76.8 & 88 & 77.9 & & & \\
\hline
\end{tabular}

*Estimated by paired Wilcoxon test (paired categorical data).

tEstimated by $\chi^{2}$ test (independent categorical data). 
Table 5 Indicators of effects of the intervention regarding determinants of fruit intake from multilevel regression analyses conducted on parent- and child-reported data, separately for children of Dutch and of non-Western ethnicity

\begin{tabular}{|c|c|c|c|c|c|c|}
\hline \multirow[b]{2}{*}{ Secondary outcome } & \multicolumn{3}{|c|}{ Parent reportt } & \multicolumn{3}{|c|}{ Child reportł } \\
\hline & $n$ & OR & $95 \% \mathrm{Cl}$ & $n$ & OR & $95 \% \mathrm{Cl}$ \\
\hline \multicolumn{7}{|l|}{ Children of Dutch ethnicity } \\
\hline \multicolumn{7}{|l|}{ Taste of the child - boys (+ girls) } \\
\hline Stable high/increased (2) & 146 & 1.00 & - & 407 & 1.00 & - \\
\hline Stable low (1) & 40 & 0.64 & $0.29-1.44$ & 59 & 1.30 & $0.73-2.31$ \\
\hline Decreased (0) & 30 & 0.26 & $0.09-0.71$ & 53 & 0.91 & $0.43-1.96$ \\
\hline \multicolumn{7}{|l|}{ Taste of the child - girls } \\
\hline Stable high/increased (2) & 183 & 1.00 & - & & & \\
\hline Stable low (1) & 22 & 1.14 & $0.45-2.92$ & & & \\
\hline Decreased (0) & 34 & 0.69 & $0.26-1.86$ & & & \\
\hline \multicolumn{7}{|c|}{ Knowledge about the recommendations } \\
\hline Stable high/increased (2) & 358 & 1.00 & - & 317 & 1.00 & - \\
\hline Stable low (1)+decreased $(0)$ & 91 & 1.43 & $0.85-2.41$ & 33 & 1.11 & $0.52-2.37$ \\
\hline Decreased (0) & & & & 142 & 0.82 & $0.53-1.25$ \\
\hline \multicolumn{7}{|c|}{ Is the child allowed to take fruit without asking? - boys (+ girls) } \\
\hline Stable high/increased (2) & 366 & 1.00 & - & 173 & 1.00 & - \\
\hline Stable low (1) & 38 & 1.73 & $0.85-3.53$ & 37 & 1.03 & $0.43-2.46$ \\
\hline Decreased (0) & 48 & 1.43 & $0.75-2.72$ & 33 & 1.86 & $0.73-4.71$ \\
\hline \multicolumn{7}{|c|}{ Is the child allowed to take fruit without asking? - girls } \\
\hline Stable high/increased (2) & & & & 177 & 1.00 & - \\
\hline Stable low (1) & & & & 60 & 0.72 & $0.39-1.34$ \\
\hline Decreased (0) & & & & 26 & 0.41 & $0.15-1.17$ \\
\hline \multicolumn{7}{|l|}{ Fruit available at home } \\
\hline Stable high/increased (2) & 434 & 1.00 & - & 440 & 1.00 & - \\
\hline Stable low $(1)+$ decreased $(0)$ & 13 & $0.94^{*}$ & $0.27-3.26^{*}$ & 76 & 1.16 & $0.62-2.16$ \\
\hline \multicolumn{7}{|l|}{ Children of non-Western ethnicity } \\
\hline \multicolumn{7}{|l|}{ Taste of the child } \\
\hline Stable high/increased (2) & 154 & 1.00 & - & 239 & 1.00 & - \\
\hline Stable low (1) & 30 & 0.28 & $0.11-0.68$ & 31 & 1.30 & $0.45-3.75$ \\
\hline Decreased (0) & 45 & 0.65 & $0.31-1.33$ & 31 & 1.85 & $0.75-4.57$ \\
\hline \multicolumn{7}{|c|}{ Knowledge about the recommendations } \\
\hline Stable high/increased (2) & 172 & 1.00 & - & 186 & 1.00 & - \\
\hline Stable low $(1)+$ decreased $(0)$ & 58 & 0.74 & $0.38-1.45$ & 15 & 0.42 & $0.12-1.47$ \\
\hline Decreased (0) & & & & 73 & 0.78 & $0.42-1.42$ \\
\hline \multicolumn{7}{|c|}{ Is the child allowed to take fruit without asking? } \\
\hline Stable high/increased (2) & 198 & 1.00 & - & 237 & 1.00 & - \\
\hline Stable low (1) & 15 & 1.48 & $0.41-5.34$ & 32 & 0.25 & $0.11-0.57$ \\
\hline Decreased (0) & 18 & 1.42 & $0.47-4.25$ & 23 & 0.58 & $0.20-1.70$ \\
\hline \multicolumn{7}{|c|}{ Fruit available at home - boys (+ girls) } \\
\hline Stable high/increased (2) & 86 & 1.00 & - & 240 & 1.00 & - \\
\hline Stable low (1)+ decreased (0) & 6 & $0.30^{*}$ & $0.05-1.83^{*}$ & 57 & 0.54 & $0.28-1.03$ \\
\hline \multicolumn{7}{|l|}{ Fruit available at home - girls } \\
\hline Stable high/increased (2) & 129 & 1.00 & - & & & \\
\hline Stable low $(1)+$ decreased $(0)$ & 8 & 1.47 & $0.24-9.13$ & & & \\
\hline
\end{tabular}

OR - odds ratio for comparison with the control group; $\mathrm{Cl}$ - confidence interval.

Analyses are adjusted for children's age, gender, region of residence of the children, and educational level of the parents.

* Not adjusted for educational level of the parents, because of empty cells.

+Parent data - for children of Dutch ethnicity, taste $\rightarrow$ an interaction $(-)$ between intervention $\times$ gender $(P=0.062)$ in the 'decreased' group; for children of nonWestern ethnicity, availability $\rightarrow$ an interaction $(-)$ between intervention $\times$ gender $(P=0.054)$.

$\ddagger$ Child data - for children of Dutch ethnicity, accessibility $\rightarrow$ an interaction between intervention $\times$ gender $(P=0.009)$ in the 'decreased' group.

Since earlier research had indicated that children from non-Western ethnicity in The Netherlands have higher intake levels and correlates of $\mathrm{F} \& \mathrm{~V}$ intakes, we explored differential effects of the intervention according to ethnicity. We hypothesised that children of non-Western ethnicity would profit less from the intervention than the children of Dutch ethnicity. This hypothesis was supported only for fruit intake, while for vegetables the intervention appeared to be somewhat more effective among the children of non-Western ethnicity. Since ethnic differences in The Netherlands are strongly confounded by educational differences, ethic differences often disappear if education is taken into account. Nevertheless, ethnicity is of course much more than education. As a secondary analysis we also conducted $a$ priori stratification according to education, testing effects separately for children from higher and lower educated parents, while adjusting for ethnicity. In these analyses, no differences in effects were found (data not shown), indicating that the observed differences between the children of Dutch ethnicity and the children of non-Western ethnicity were not the result of differences in educational level of the parents.

All effects regarding usual intake levels were found in the child-reported data. These effects were not confirmed 
in analyses of the parent-report data. This may partly be due to power issues, since parent-report data were available for fewer children. The parent-reported mean F\&V intakes at baseline and follow-up for the intervention and control groups (Table 2) do indicate that the mean intake levels between baseline and follow-up were more positive in the intervention group. Parental reports are considered useful because two-thirds of schoolchildren eat at home during the lunch break in The Netherlands ${ }^{36}$, and parents are responsible for availability and accessibility of foods at home. When the children stay at school, they bring their own lunch and snacks, as no school meals are offered and no food can be obtained from vending machines or otherwise, and children are not allowed to leave the school or schoolyard during school hours. Nevertheless, it must be realised that the parents did not directly observe the main part of the present intervention: the distribution of $\mathrm{F} \& \mathrm{~V}$ on two schooldays per week. It may therefore be that the child reports were more sensitive to changes induced by this particular intervention. On the other hand, since the children were much more intensively exposed to intervention activities than the parents, it may also be that the children in the intervention group were more likely to give socially desirable answers, and that this led to higher intake reports compared with the control group.

\section{Conclusion}

The present study provides some evidence that the Schoolgruiten intervention was effective in increasing the fruit intake of children of Dutch ethnicity and increasing the vegetable intake of children of non-Western ethnicity (according the child data).

In addition, we observed positive intervention effects for taste preference and increased accessibility among the children of non-Western ethnicity.

\section{Acknowledgements}

Sources offunding: Funding for this study was provided by The Dutch Ministry for Health, Welfare and Sport and Holland Produce Promotion in Zoetermeer. The contribution of N.I.T. is funded by The World Cancer Research Fund (grant no. 2004/05). The contribution of S.J.t.V. is funded by The Netherlands Organization for Health Research and Development (ZonMw) Program for Prevention (no. 6200.0003).

Conflict of interest declaration: The authors declare that they have no competing interests.

Authorship responsibilities: N.I.T. collected and analysed the data and drafted the manuscript. S.J.t.V. and J.B. participated in the study design and provided critical revision of the manuscript. All three authors have read and approved the final manuscript.

Acknowledgements: We thank the schools and schoolchildren for participating in this study.

\section{References}

1 Yngve A, Wolf A, Poortvliet E, Elmadfa I, Brug J, Ehrenblad B, et al. Fruit and vegetable intake in a sample of 11-year-old children in 9 European countries: the Pro Children crosssectional survey. Annals of Nutrition \& Metabolism 2005; 49: $236-45$.

2 World Health Organization. Promoting fruit and vegetable consumption around the world [online], 2005. Available at http://www.who.int/dietphysicalactivity/fruit/en/. Accessed 2 October 2005.

3 Van Duyn MAS, Pivonka E. Overview of the health benefits of fruit and vegetable consumption for the dietetics professional: selected literature. Journal of the American Dietetic Association 2000; 100: 1511-21.

4 Bes-Rastrollo M, Martinez-Gonzalez MA, Sanchez-Villegas A, De la Fuente Arrillaga C, Martinez JA. Association of fiber intake and fruit/vegetable consumption with weight gain in a Mediterranean population. Nutrition 2006; 22: 504-11.

5 Te Velde SJ, Twisk JWR, Brug J. Tracking of fruit and vegetable consumption from adolescence into adulthood and its longitudinal association with overweight. British Journal of Nutrition 2007; 16: 1-8 [Epub ahead of print].

6 Rozin P. Development in the food domain. Developmental Psychology 1990; 26: 555-62.

7 Kelder SH, Perry CL, Klepp KI, Lytle LL. Longitudinal tracking of adolescent smoking, physical activity, and food choice behaviors. American Journal of Public Health 1994; 84: 1121-6.

8 Klepp KI, Pérez-Rodrigo C, De Bourdeaudhuij I, Due P, Elmadfa I, Haraldsdóttir J, et al. Promoting fruit and vegetable consumption among European schoolchildren: rationale, conceptualization and design of the Pro Children Project. Annals of Nutrition \& Metabolism 2005; 49: 212-20.

9 Birch LL. Development of food acceptance patterns. Developmental Psychology 1990; 26: 515-19.

10 Anon. Zo eet Nederland [This is How the Dutch Eat]. Den Haag: Voedingscentrum, 1998 (in Dutch).

11 Wind M, Van Zadelhoff W, Snel J, Van der Ham E, Brug J. Groente- en fruitconsumptie van basisschoolkinderen bevorderen. Verschillende interventies [Promoting fruit and vegetable intake among primary schoolchildren. Different interventions]. Voeding $N u$ 2004; 3: 21-3 (in Dutch).

12 Te Velde SJ, Wind M, Van Lenthe FJ, Klepp KI, Brug J. Differences in fruit and vegetable intake and determinants of intakes between children of Dutch origin and nonWestern ethnic minority children in the Netherlands - a cross sectional study. International Journal of Behavioral Nutrition and Physical Activity 2006; 3: 31.

13 Dijkshoorn H. Ongezonde gewoonten in Amsterdam; verschillen tussen Turken, Marokkanen en Nederlanders: Amsterdamse Gezondheidsmonitor 1999-2000 [Unhealthy Behaviours in Amsterdam; Differences between Turks, Moroccans and the Dutch. The Amsterdam Health Monitor 1999-2000]. Amsterdam: Gemeentelijke Geneeskundige Gezondheidsdienst Amsterdam, 2002 (in Dutch).

14 van Leest LATM, van Dis SJ, Verschuren WMM. Hart-en vaatziekten bij allochtonen in Nederland. Een ciffermatige verkenning naar leefstijl- en risicofactoren, ziekte en sterfte [Cardiovascular Diseases among Allochtonous People in 
The Netherlands. An Exploratory Investigation of Life Style and Risk Factors, Disease and Mortality]. Bilthoven: National Institute for Public Health and Environment (RIVM), 2002 (in Dutch).

15 van Bergen A, Dittrich H, Gelderloos G, Hesselink M, Hofmeijer A. Volksgezondheidsmonitor Utrecht - themarapport Allochtonen 19-65 jaar [Public Health Monitor Utrecht - Theme Report non-Western Immigrants 19-65 years]. Utrecht: Gemeentelijke Geneeskundige Gezondheidsdienst Utrecht, 2003 (in Dutch).

16 Brussaard JH, Brants HAM, Van Erp-Baart AMJ, Hulshof KFAM. Voedselconsumptie en voedingstoestand bij 8-jarige Marokkaanse, Turkse en Nederlandse kinderen en bun moeders [Food Consumption and Feeding State of 8-yearold Moroccans, Turkish and Dutch Children and their Mothers]. Zeist: TNO Nutrition and Food Research, 2000 (in Dutch).

17 Bere E, Klepp KI. Correlates of fruit and vegetable intake among Norwegian schoolchildren: parental and selfreports. Public Health Nutrition 2004; 7: 991-8.

18 Bere E, Klepp K. Reliability of parental and self-reported determinants of fruit and vegetable intake among 6th graders. Public Health Nutrition 2004; 7: 353-6.

19 Wind M, De Bourdeaudhuij I, Te Velde SJ, Sandvik C, Klepp KI, Due P, et al. Correlates of fruit and vegetable consumption among 11-year-old Belgian-Flemish and Dutch schoolchildren. Journal of Nutrition Education $\varepsilon$ Behavior 2006; 38: 211-21.

20 De Bourdeaudhuij I, Klepp KI, Due P, Rodrigo CP, de Almeida MDV, Wind M, et al. Reliability and validity of a questionnaire to measure personal, social and environmental correlates of fruit and vegetable intake in 10-11year-old children in five European countries. Public Health Nutrition 2005; 8: 189-200.

21 Blanchette L, Brug J. Determinants of fruit and vegetable consumption among 6-12-year-old children and effective interventions to increase consumption. Journal of Human Nutrition and Dietetics 2005; 18: 431-43.

22 Baranowski T, Cullen KW, Baranowski J. Psychosocial correlates of dietary intake: advancing dietary intervention. Annual Review of Nutrition 1999; 19: 17-40.

23 Wardle J, Herrera ML, Cooke L, Gibson EL. Modifying children's food preferences: the effects of exposure and reward on acceptance of an unfamiliar vegetable. European Journal of Clinical Nutrition 2003; 57: 341-8.

24 Dutch Ministry of Education, Culture and Science. Onderwijs - primair onderwijs [Education - primary education] [online], 2006. Available at http://www.minocw.nl/onderwijs/ 393/index.html/. Accessed 7 April 2006 (in Dutch).
25 Haraldsdottir J, Thorsdottir I, de Almeida MD, Maes L, Perez Rodrigo C, Elmadfa I, et al. Validity and reproducibility of a precoded questionnaire to assess fruit and vegetable intake in European 11- to 12-year-old schoolchildren. Annals of Nutrition \& Metabolism 2005; 49: 221-7.

26 Kristjansdottir AG, Andersen LF, Haraldsdottir J, De Almeida MDV, Thorsdottir I. Validity of a questionnaire to assess fruit and vegetable intake in adults. European Journal of Clinical Nutrition 2006; 60: 408-15.

27 Statistics Netherlands. Begrippen [Definitions and terminology] [online], 2005. Available at http://www.cbs.nl/nl-NL/ menu/methoden/begrippen/default.htm?conceptid=1013/. Accessed 7 December 2005 (in Dutch).

28 Tak NI, Te Velde SJ, De Vries JHM, Brug J. Parent and child reports of fruit and vegetable intakes and related family environmental factors show low levels of agreement. Journal of Human Nutrition and Dietetics 2006; 19: 275-85.

29 Twisk JWR, Proper K. Evaluation of the results of a randomized controlled trial: how to define changes between baseline and follow-up. Journal of Clinical Epidemiology 2004; 57: 223-8.

30 Anon. A User's Guide to MLwiN Version 2.02 [program]. London: Institute of Education, 2004.

31 Eriksen K, Haraldsdottir J, Pederson R, Flyger HV. Effect of a fruit and vegetable subscription in Danish schools. Public Health Nutrition 2003; 6: 57-63.

32 Bere E, Veierod MB, Klepp KI. The Norwegian School Fruit Programme: evaluating paid vs. no-cost subscriptions. Preventive Medicine 2005; 41: 463-70.

33 Pérez-Rodrigo C, Wind M, Hildonen C, Bjelland M, Aranceta J, Klepp KI, et al. The Pro Children Intervention: applying the intervention mapping protocol to develop a schoolbased fruit and vegetable promotion programme. Annals of Nutrition \& Metabolism 2005; 49: 267-77.

34 Livingstone MBE, Robson PJ. Measurement of dietary intake in children. Proceedings of the Nutrition Society 2000; 59 : 279-93.

35 Hammond J, Nelson M, Chinn S, Rona RJ. Validation of a food frequency questionnaire for assessing dietary intake in a study of coronary heart disease risk factors in children. European Journal of Clinical Nutrition 1993; 47: $242-50$.

36 Dutch Ministry of Education Culture and Science. Overblijven schoolkinderen kan beter geregeld [Staying at school for lunch can be organized better] [online], 2005. Available at http://www.minvws.nl/nieuwsberichten/djb/ overblijven_schoolkinderen_kan_beter_geregeld.asp. Accessed 18 October 2005 (in Dutch). 